\title{
Community of Inquiry in an Online Undergraduate Information Technology Course
}

\author{
Lim Hwee Ling \\ The Petroleum Institute, Abu Dhabi, UAE
}

hlim@pi.ac.ae

\section{Executive Summary}

The Community of Inquiry (COI) theoretical framework suggests that successful higher education experiences are supported by the presence and interaction of cognitive, social and teaching elements. Since the COI model has been widely used for examining quality of asynchronous computer-mediated communication (CMC) educational interactions, its applicability to synchronous CMC interactions is relatively unknown. Moreover, as the model's coding scheme was mainly designed for analyzing online asynchronous discussions, it is more sensitive to longer postings than the shorter and more discursive exchanges present in online synchronous (chat) discourse.

This paper presents a case study on the instructional application of online synchronous interaction in a distance IT undergraduate course from a sociocultural constructivist perspective. The case involved two tutorial groups engaged in collaborative learning situated in WebCT chat rooms. The study focuses on identifying cognitive, social and teaching presences from the analyses of student experiences and chat exchanges during moderated virtual tutorial discussions. A web survey was administered to student respondents on the extent of peer/tutor learning support perceived to be available. Also, chat transcripts, reflecting dialogic participation in tutorial discussions, were analyzed using a refined Exchange Structure Analysis scheme.

Survey results indicated presences of cognitive and teaching elements as student perceptions of tutor/peer efforts in clarifying and providing different ideas during discussions. Similarly, discourse analysis findings showed contribution of turns conveying content directly related to learning activities, thus indicating presence of the cognitive element. Off-Topic turns were contributed for developing social relations, dealing with class management and technical matters. Interestingly, marked differences emerged in tutors' efforts to establish cognitive presence. Overall, when interpreted within the COI model, the results revealed that all three elements that constitute an effective online educational experience were present in the chat tutorial environment.

Given the constructivist view that the learner's potential capacity for intellectual growth is enhanced by scaffolding through interaction, the different extent of tutor learning support found presents pedagogical implications. It is recommended that online tutors adopt the cyclical activity

Material published as part of this publication, either on-line or in print, is copyrighted by the Informing Science Institute. Permission to make digital or paper copy of part or all of these works for personal or classroom use is granted without fee provided that the copies are not made or distributed for profit or commercial advantage AND that copies 1) bear this notice in full and 2) give the full citation on the first page. It is permissible to abstract these works so long as credit is given. To copy in all other cases or to republish or to post on a server or to redistribute to lists requires specific permission and payment of a fee. Contact Publisher@InformingScience.org to request redistribution permission. of reflection on educator practice to enhance awareness of the effects of cognitive, social, and teaching presences on learning experiences.

Keywords: online synchronous communication, collaborative learning, sociocultural constructivism, discourse analysis, student experiences. 


\section{Introduction}

Within the Community of Inquiry theoretical framework (Garrison, Anderson, \& Archer, 2000), a successful higher education experience is held to be supported by the presence and interaction of the elements of cognitive, social and teaching presences. Although the framework has been extensively used, from a constructivist perspective, to examine the quality of asynchronous educational interactions enabled by computer-mediated communication (CMC) media such as e-mail and discussion forums, less is known about its applicability to the more discursive educational exchanges facilitated by the synchronous CMC medium. This paper describes an innovative case of the instructional application of online synchronous (chat) interaction in a distance IT undergraduate course that enabled the examination of the three presences during tutorial discussions. Results from discourse analysis of chat exchanges and web survey of student learning experiences during collaborative group learning processes in virtual tutorials are presented. The paper concludes with discussion on the implications of findings for guiding the pedagogical design of online synchronous instructional environments that facilitate collaborative group learning processes in distance educational programmes.

\section{Background}

Interaction is considered crucial to learning experiences from the sociocultural constructivist perspective (Vygotsky, 1962) which assumes that participation in discursive practices of the community supports knowledge construction. Furthermore, the learner's potential capacity for intellectual growth is held to be enhanced by the presence of scaffolding or guidance in the form of tutor/peer support through interaction. In online educational contexts, the move from constructing learning conversations in traditional classrooms to virtual settings presents benefits and challenges to educators as the range of educational interactions has been extended yet limited by technological decisions.

Moore (1989) introduced three types of interaction now widely described and accepted in the field of distance education: learner-content, learner-instructor, and learner-learner interactions. With greater acceptance of constructivist learning approaches and improved web/CMC technologies, learner-learner interaction represents a new dimension in distance education which normally eschews group/collaborative learning approaches due to the geographically separated learning parties.

Extending on these three basic interaction types, Anderson and Garrison (1998) proposed that online transactions could occur between three macro-components of student, teacher, and content producing student-teacher, student-content, and teacher-content interaction types. In addition, transactions within each macro-component could result in a sub-set of interactions: studentstudent, teacher-teacher, and content-content. In order to contextualize these interactions, Garrison Anderson and Archer (2000) developed a Community of Inquiry (COI) model which was elaborated on and refined in subsequent publications (Anderson, 2004; Garrison, 2003; Garrison \& Anderson, 2003; Kanuka \& Garrison, 2004). The following discussion draws from these main sources in describing the model.

According to Garrison and Anderson (2003), the term 'community of inquiry' was originally used by Lipman (1991) to refer to a teacher-facilitated critical learning community where "students listen to one another with respect, build on one another's ideas, challenge one another to supply reasons for otherwise unsupported opinions, assist each other in drawing inferences from what has been said, and seek to identify one another's assumptions" (Lipman, 1991, p.15 in Garrison \& Anderson, 2003, p.27). Based on this broad concept of a critical learning community comprising students and teachers and the constructivist assumption that knowledge building is a contextualized social process which occurs within such a community, the COI model is conceived as com- 
prising three mutually interacting and reinforcing elements of cognitive, social, and teaching presences supported in online instructional environments by CMC technologies (Figure 1). The formation of such a community in online learning contexts represents an environment for "critical discourse and reflection" (Garrison \& Anderson, 2003, p.27) where the dialogic education experience of sharing and negotiation of understandings could lead to "higher levels of learning" (Kanuka \& Garrison, 2004, p.4).

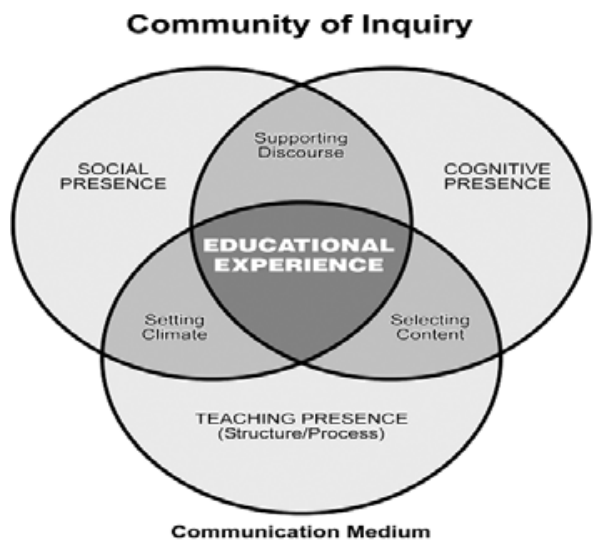

Figure 1: Community of Inquiry Model (Garrison, Anderson, \& Archer, 2000)

In the COI model, cognitive presence is defined as "the extent to which participants in any particular configuration of a community of inquiry are able to construct meaning through sustained communication" (Garrison et al., 2000, p.4). The construct was also used to refer to "the intellectual environment that supports sustained critical discourse and higher-order knowledge acquisition and application" (Garrison \& Anderson, 2003, p.55).

Social presence, a term first coined by Short, Williams, and Christie (1976), is used in this model to refer to "the ability of participants in the Community of Inquiry to project their personal characteristics into the community, thereby presenting themselves to the other participants as 'real people" through the means of communication utilized (Garrison et al., 2000, p.4).

Teaching presence is defined in terms of three functions, namely, "the design, facilitation and direction of cognitive and social processes for the purpose of realizing personally meaningful and educationally worthwhile learning outcomes" (Anderson, Rourke, Garrison, \& Archer, 2001, p.5). Although normally regarded as the main responsibility of the teacher, the constructivist orientation of the COI model holds that the teaching presence could also be established to some degree by a re-definition of student roles and through student-content interactions (Rourke, Anderson, Garrison, \& Archer, 2001).

The presence and interactions between these three elements in the COI model are considered "crucial prerequisites for a successful higher education experience" (Garrison et al., 2000, p.2). The cognitive presence reflects the intellectual climate (Garrison, 2003) of the learning environment with the instructional objectives justifying its existence to the participants. The perception of an open or unthreatening social climate facilitates the knowledge sharing process necessary to sustain cognitive presence while the teaching presence structures and mediates the three components (Anderson, Rourke, Garrison, \& Archer, 2001). However, as educational communities are usually formed to attain "intended cognitive outcomes" (Garrison \& Anderson, 2003, p.55), in this model, the social and teaching presences have mainly supportive or facilitative roles in the learning process. 
Garrison, Anderson, and Archer (2001) operationalized the elements as a template of categories and accompanying indicators that was used in a number of studies for identifying and evaluating social presence (Rourke, Anderson, Garrison, \& Archer, 2001; Stacey, 2000; Ubon \& Kimble, 2004), teaching presence (Anderson et al., 2001; Stein \& Wanstreet, 2004) and cognitive presence (Garrison, 2003; Garrison et al., 2001; Kanuka \& Garrison, 2004; McKlin, Harmon, Evans, \& Jones, 2002; Meyer, 2003; Pawan, Paulus, Yalcin, \& Chang, 2003) in asynchronous interactions in online higher education contexts.

However, the applicability of the COI model to interactions facilitated by synchronous CMC technology, in higher education, is relatively unknown. Researchers have observed that chat has only recently been applied for instructional purposes (Murphy \& Collins, 1997) which could be due to perceptions such as "promoting active asynchronous discussion is the best way to support interactivity in the online course" (Palloff \& Pratt, 2003, pp.24-25) and that chat is useful primarily for building social relations in distant learning groups (Lapadat, 2002). Additionally, the synchronicity and conversational characteristics (Kortti, 1999) of chat interaction led to unfavourable comparisons with the asynchronous CMC mode on aspects of time constraint for extended reflection on learning, availability of participation opportunities due to the rapid discussion speed and competition for the 'speaking' floor (Meyer, 2003), and additional skills (typing, language fluency) required of tutors and learners for managing or coping with chat interaction and its discourse (Dykes \& Schwier, 2003; Warschauer, 1996).

While some studies have investigated social presence in online synchronous interaction as the social-emotional aspects of collaborative learning and work group processes (Chou, 2002; Duemer, Fontenot, Gumfory, \& Kallus, 2002; Mercer, 2003; Schwier \& Balbar, 2002; Sudweeks \& Simoff, 2000), the presence of all three elements in online synchronous learning environments remains relatively unknown. Additionally, the template of categories/indicators (Garrison et al., 2001) was mainly designed for analyzing online asynchronous discussions and hence more sensitive when applied to longer postings than the shorter, condensed and more intense exchanges present in chat discourse.

Such a situation highlights the need to further current understanding on the design of online synchronous learning environments that encompass interactions between cognitive, social, and teaching presences which could facilitate dialogic construction of knowledge. A rare yet innovative case of the instructional application of chat interaction in a distance IT undergraduate course, described below, enabled a recent case study (Lim, 2006) on the quality of collaborative group learning processes facilitated by the synchronous CMC technology. This paper presents a subset of findings from the larger study focusing on the identification of cognitive, social and teaching presences in the case from the analyses of student experiences and educational chat discourse during moderated virtual tutorial discussions. The paper also describes the application of a refined Exchange Structure Analysis (Cox, Carr, \& Hall, 2004; Kneser, Pilkington, \& Treasure-Jones, 2001 ) instrument for the analysis of chat exchanges and concludes with a discussion on the implications of findings for the pedagogical design of online synchronous instructional environments.

\section{The Case Study}

\section{About Organisational Informatics}

The case was an undergraduate unit of study, within the Bachelor of Science degree, offered by the School of Information Technology at Murdoch University (Perth, Western Australia). The Organisational Informatics (OI) unit, which focuses on computer-mediated work processes, is available in the second semester (13 weeks) of each academic year to third-year students. The unit adopts a hybrid course delivery design that offers face-to-face lectures and online synchro- 
nous (chat) tutorials to internal and external students who, respectively, undergo the course oncampus and via a distance learning mode.

The OI unit aims to develop skills associated with organizational aspects of information systems design and development (Sudweeks, 2004), including skills in critical assessment and management of issues related to knowledge building organizations by facilitating knowledge construction through reflection. The unit's constructivist (Vygotsky, 1962) pedagogical framework regards learning as "a cycle of interpretation, evaluation and reflection of content evolving into individual and shared knowledge" (Sudweeks \& Simoff, 2000, section 3). Hence, instructional strategies emphasize "collaboration, personal autonomy, generativity, reflectivity, active engagement, personal relevance, and pluralism" (Sudweeks, 2004, p.83).

The unit's main learning activities comprise a group project and online tutorial discussions which are designed to facilitate students' construction of knowledge through participation and reflection. Online interactions during these activities are supported by CMC media including e-mail, bulletin boards and chat. This paper focuses on the online synchronous interaction during chat tutorials. The next section describes the virtual learning environment of the unit, the chat tutorial activity and its participants that formed the case study.

\section{The Virtual Learning Environment}

The main learning resources for the OI unit include a print Resource Materials reader and electronic resources from the unit home page (Figure 2) which is available via WebCT. WebCT is a commercial learning management system currently adopted by Murdoch University as its university-wide virtual learning environment (VLE). WebCT also provides a range of synchronous and asynchronous $\mathrm{CMC}$ technologies described below for facilitating educational interactions.

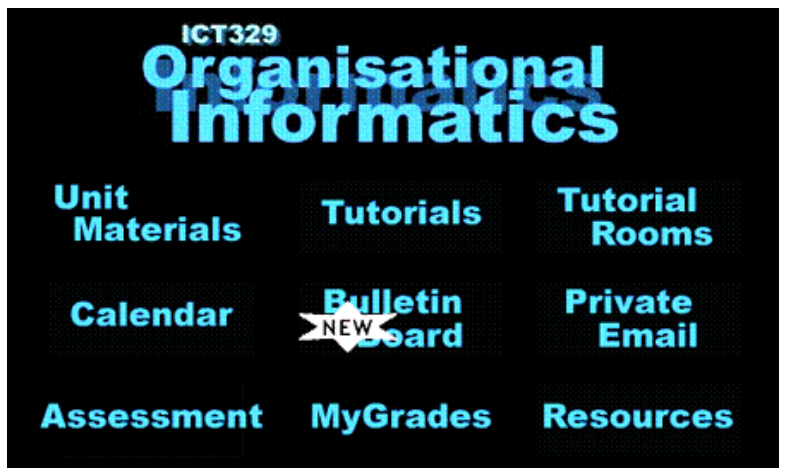

Figure 2: 2005 Organisational Informatics Home Page

The VLE structure in 2005 is depicted in Figure 3. It should be noted that some VLE elements perform overlapping functions; for instance, the calendar could be a communication tool for conveying noteworthy events and an administration tool for organizing public and/or private diary entries. Similarly, the tutor contact details/photo could function as an administration element or a supporting resource element for establishing social presence of the online instructor.

From this perspective, the VLE is organized into three main components: communication, unit materials, and administration. The communication component includes synchronous and asynchronous communication tools such as WebCT chat (Figure 4), bulletin boards, private e-mail, and a common calendar. The administrative component supports course organizational services such as self-enrolment in tutorial groups through the Online Tutorial Signup System (OTSS), the distribution of grades, access to lecture/tutorial schedules, and the Unit Outline. The unit materials component comprises three sub-categories of learning materials: content materials, support resources, and assessment resources. Content materials and support resources provide access to 
main and secondary instructional materials such as iLecture notes (streamed audio links) and links to external sites. The assessment sub-category provides access to assignments resources such as project requirements and peer assessment forms.

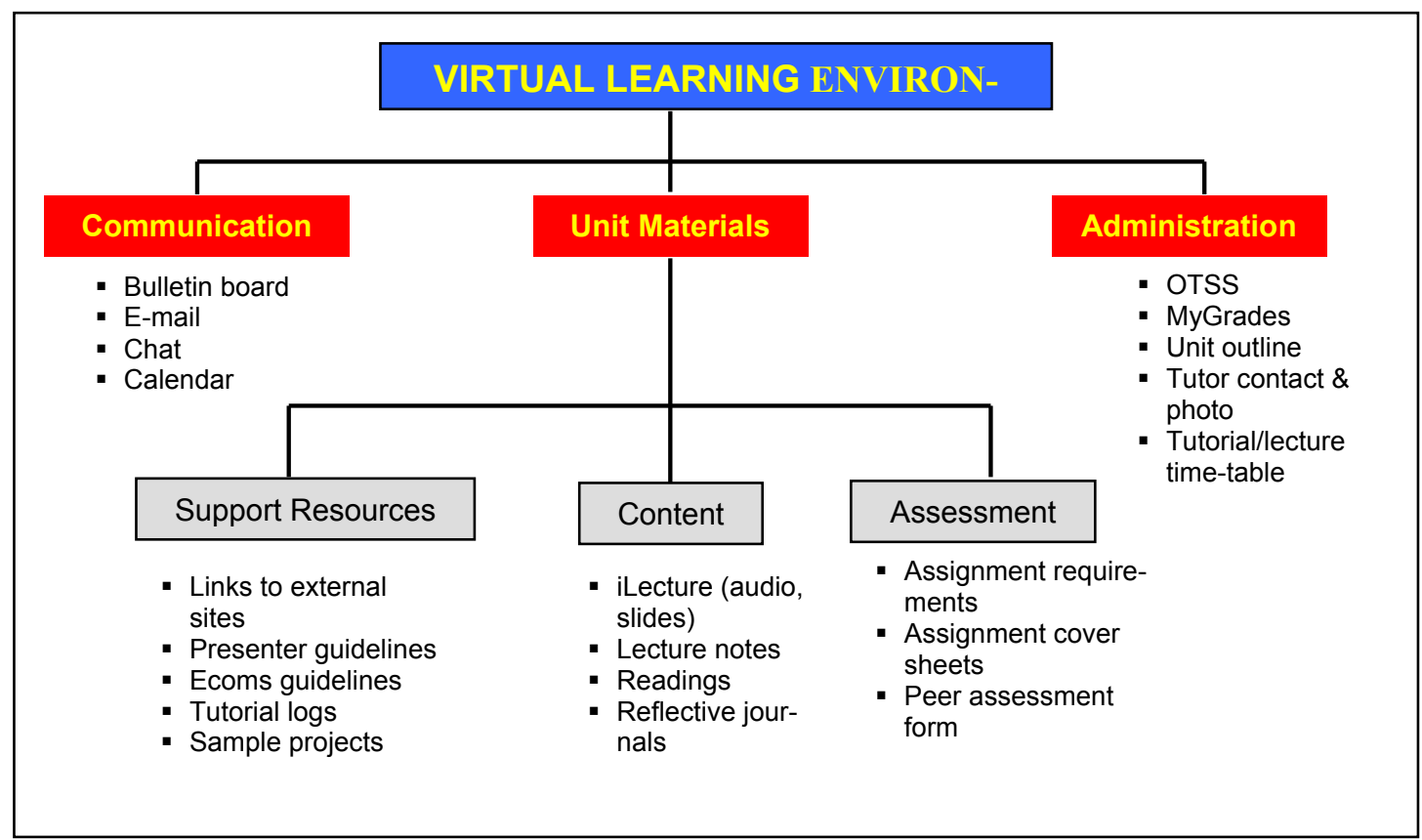

Figure 3: 2005 Representation of Organisational Informatics VLE

(adapted from Sudweeks, 2003a, p.176)

There is significant use of the VLE as "a digital educational environment" (Sudweeks, 2004, p.92) where students could access resources for their educational needs and the management of learning processes. The VLE also provides online spaces where learning could be situated in synchronous and asynchronous environments. Moreover, there is extensive use of CMC to not only support interaction during chat tutorials and the collaborative group work processes for the group project, but also to facilitate unit administration or assessment, such as electronic submission of coursework to the tutor via e-mail or posting of student critiques of readings as journals to the bulletin board. Essentially, the VLE plays a vital role in reducing transactional distance (Moore \& Kearsley, 1996) usually perceived by students in distance courses.

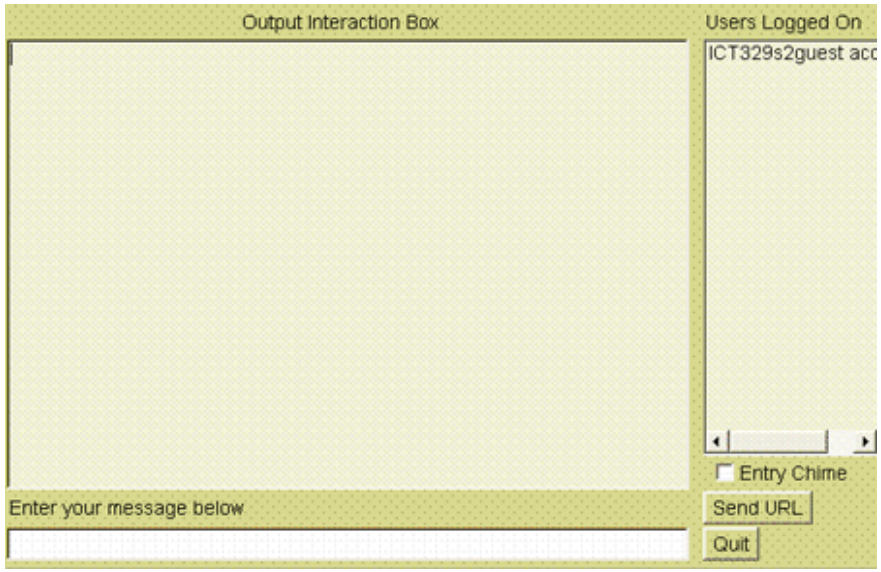

Figure 4: WebCT Chat Facility 


\section{The Participants}

The case study involved two tutorial groups; Groups 1 and 4 (Table 1), out of four available, who were engaged in collaborative learning during a series of 11 online tutorial sessions over a 13week semester in 2005. All groups underwent equivalent learning activities that took place in WebCT chat rooms. The participants were students from tutorial groups 1 and 4, two tutors and the researcher. The names used here are pseudonyms except for Fay (tutor, unit coordinator) and Lim (author).

Table 1: Characteristics of Tutorial Groups 1 and 4

\begin{tabular}{|c|c|c|}
\hline Characteristics & Group 1 & Group 4 \\
\hline Group tutor & - Rachel (Part-time) & - Fay (Full-time, unit coordinator) \\
\hline Group size & - 15 students, 1 tutor & - 9 students, 1 tutor, 1 researcher (Lim) \\
\hline Enrolment status & - 13 internal, 2 external students & - 4 internal, 5 external students \\
\hline Nationality & $\begin{array}{l}\text { - Majority of international students, } \\
\text { minority of Australian students }\end{array}$ & $\begin{array}{l}\text { - Majority of Australian students, } \\
\text { - minority of international students }\end{array}$ \\
\hline $\begin{array}{l}\text { English Language } \\
\text { proficiency }\end{array}$ & $\begin{array}{l}\text { - Majority of ESL/EFL speakers, } \\
\text { minority of native English speakers }\end{array}$ & - All native English speakers \\
\hline Gender & - 3 female and 12 male students & - 1 female and 8 male students \\
\hline
\end{tabular}

\section{The Online Synchronous Tutorial}

The chat tutorials are designed to develop "reflective construction of knowledge and active participation" (Sudweeks, 2004, p.85), and sustain "students' continuous engagement in discovering and applying knowledge and skills in the context of authentic problem solving" (p.92). Preparation for the tutorial activity is supported by resources from the VLE such as the Reflective Journal which states the requirements for the critique; Guidelines for Tutorial Presenters which states the responsibilities of the presenter; and Ecoms Guidelines which highlights CMC conventions and netiquette.

The weekly tutorials are conducted in a seminar style, with a tutor-facilitator and one or two student presenters moderating the discussion. The presenter role is rotated among all the students in each tutorial group. In more detail, a presenter moderates a $1 / 2$ hour discussion slot in the one-hour tutorial session based on his/her critiques of the week's readings. During the tutorial, the presenter starts the discussion by highlighting the main issues in the selected reading(s) and moderates the discussion by posing questions and encouraging participation by all (Sudweeks, 2003b). The tutor is present as a facilitator, evaluates the presenter's performance and the quality of participation by other students. The other students are expected to participate actively in discussions; guided by peers' critiques as journals posted in bulletin boards, and evaluate the presenter with the aid of archived discussion logs.

In congruence with the pedagogical aims of the tutorial activity, tutor/peer assessment of participation emphasize quality of participation, collaborative effort, and sense of responsibility displayed. Essentially, the constructivist pedagogical framework of the unit is reflected in the tutorial activity that involves critical review of readings, dialogic exchange of multiple perspectives, and student reflection on learning.

Additionally, it is possible to regard the tutorials as virtual learning environments that reflect the COI model. As student presenters moderate by drawing less confident members into discussions, supporting views of others and keeping discussions relevant under the guidance of the tutorfacilitator, both the presenters and the tutor would be involved in establishing teaching presence in the online environment. Furthermore, as all parties share individual knowledge, negotiate new understandings during dialogic interaction, build relational ties that bind virtual communities, 
they would essentially be engaged in providing cognitive and social support to each other. Hence, in transferring the theoretical model to the online synchronous learning environment, the following assumptions could be made:

The teaching presence is assumed to be reflected in the design of course materials or activities that structure the learning process, the specific instructional goals established for chat tutorials, and in the events of direct instruction and/or facilitation (carried out by the tutor and/or student-presenters) during the tutorial discussions.

Even as there are concerns regarding the use of a 'lean' text-based CMC medium (Daft \& Lengel, 1986) to convey social-emotional elements, it is assumed that compared to the asynchronous CMC mode, social presence could be more readily established with the synchronous $\mathrm{CMC}$ mode which provides additional dimensions of immediacy and the natural conversational rhythm of face-to-face exchanges (Werry, 1996).

The cognitive presence is assumed to be supported by both elements of social and teaching presences with the knowledge construction process held to be reflected in the taskoriented chat exchanges, which are contributions that reflect content directly relevant to the learning activities, as well as in student self-reflections on experiences of tutor/peer learning support.

The availability of this particularly information rich case (Patton, 2002) enabled these assumptions to be explored using the methods of survey perception and discourse analyses described in the next section.

\section{The Methods}

At the end of the semester, a web survey was administered to 23 student respondents from both tutorial groups with return rates of $93 \%(\mathrm{G} 1)$ and $89 \%(\mathrm{G} 4)$. The questionnaire included openended and closed questions on various aspects of overall learning experiences during chat tutorials. Responses to closed questions were subjected to simple descriptive statistical analysis. Findings from the closed questions are presented on the extent of peer/tutor learning support perceived to be available which could indicate the presence of cognitive and teaching elements in the online synchronous interactions.

In the larger study (Lim, 2006), the approach of discourse analysis (Brown \& Yule, 1983), defined as a textual analysis procedure for studying "texts and talk in social practice" (Hepburn \& Potter, 2004, p.180), was adopted for examining quality of educational chat interaction present in G1 and G4 discussion logs. The chat transcripts, reflecting dialogic participation in critical discussions, were analyzed using a refined Exchange Structure Analysis (ESA) scheme described briefly below, which extends the works of Cox et al. (2004) and Kneser et al. (2001).

Reflecting the structure of conventional conversational exchanges (Coulthard \& Brazil, 1992; Pilkington, 1999), a well-formed chat exchange is held to comprise at least an initiating and a responding turn, performed by a minimum of two participants. While in spoken discourse, a turn is usually delimited by the start and end of a participant speaking, in chat discourse, "a carriage return effectively sends a message and automatically delimits a turn" (Kneser et al., 2001, p.67). A turn consists of at least one move indicating its pragmatic intention at speech act level (Austin, 1962; Searle, 1969).

The ESA scheme analyzes pedagogical chat exchanges at two main levels: Exchange Structure (ES) and Move levels. In each episode (a $1 / 2$ hour discussion slot in the 1 hour tutorial session), task-oriented turns or contributions reflecting content directly relevant to the learning activities, are first coded at ES level according to four structural categories: Initiate (I), Reinitiate (RI), Respond (R), or Response-Complement (RC) to derive exchanges, as shown below. At the Move 
level, coded turns are further classified according to their associated moves. For instance, an (I) turn could be coded at the Move level as having the pragmatic intention to Inquire \{INQ\}.

Example: ES and Move level analyses of a pedagogical chat exchange

Participant $\mathrm{A} \gg>$ did you do ICT108? you should know why
the internet was first developed
Participant $\mathrm{B} \gg>$ Shmm wasn't the internet made for the army or
Sarticipant $\mathrm{C}>>$ sarpa
Participant $\mathrm{A}>>$ military, yes

* $\{\mathrm{INQ}\}$-to Inquire; $\{\mathrm{CHK}\}$-to Check; $\{\mathrm{INF}\}$-to Inform; $\{\mathrm{FBK}\}$-to Feedback.

As there may be turns within episodes that do not reflect content directly relevant to the learning activities, a separate Other category (Table 2) was created for such non task-oriented turns which are not coded at ES or Move level. These turns are classified as Off-Topic (OT) or Repair (RPR) with the latter serving to 'repair' or correct (Schegloff, Jefferson, \& Sacks, 1977) a previous turn. The OT turns, which are of greater relevance here, are further sub-categorized as the following:

- OT-Social (OT-S) turns that support development of relationships such as greetings, social banter and emoticons;

- OT-Administration (OT-A) turns that deal with housekeeping issues for the OI unit and/or tutorial group such as time-calls and reminders; and

- OT-Technical (OT-T) turns that result from technical problems/issues such as mistyping and problems with network connections or equipment.

Table 2: Other Coding Categories in the ESA Scheme

\begin{tabular}{|c|c|c|c|}
\hline \multicolumn{2}{|c|}{ OTHER Category and Descriptors } & \multicolumn{2}{|l|}{ Examples from chat transcript } \\
\hline \multicolumn{4}{|l|}{ (OT) Off-Topic } \\
\hline & $\begin{array}{l}\text { OT-Social (OT-S) } \\
\text { - supports development of } \\
\text { relationships such as } \\
\text { greetings, social banter } \\
\text { and emoticons }\end{array}$ & $\begin{array}{l}\text { Participant }>>\text { Hes a married man! } \\
\text { Participant }>>\text { Thank you }\end{array}$ & $\begin{array}{l}\text { OT-S } \\
\text { OT-S }\end{array}$ \\
\hline & $\begin{array}{l}\text { OT-Administration (OT-A) } \\
\text { - deals with housekeeping } \\
\text { issues for the OI unit } \\
\text { and/or tutorial group such } \\
\text { as time-calls and remind- } \\
\text { ers }\end{array}$ & $\begin{array}{l}\text { Participant } \gg>3 \text { mins } \\
\text { Participant } \gg>\text { Thanks, do you want to wrap it up? }\end{array}$ & $\begin{array}{l}\text { OT-A } \\
\text { OT-A }\end{array}$ \\
\hline & $\begin{array}{l}\text { OT-Technical (OT-T) } \\
\text { - results from technical prob- } \\
\text { lems/issues such as mistyping and } \\
\text { problems with network connec- } \\
\text { tions or equipment. }\end{array}$ & $\begin{array}{l}\text { Participant }>>\text { i dowhy? } \\
\text { Participant }>>\text { [blank] }\end{array}$ & $\begin{array}{l}\text { OT-T } \\
\text { OT-T }\end{array}$ \\
\hline \multirow[t]{3}{*}{ (RPR) Repair } & $\begin{array}{l}\text { - to repair or correct a pre- } \\
\text { vious turn }\end{array}$ & & \\
\hline & $\begin{array}{l}\text { Repair-Self (RPR-S) whereby the } \\
\text { 'speaker' of the trouble-source } \\
\text { carries out the repair }\end{array}$ & $\begin{array}{l}\text { Participant } \mathrm{A}>>\text { and the results can be found in a } \\
\text { long term... which most manager want it S.O.S } \\
\text { Participant } \mathrm{A} \gg>\text { I mean sonn as possible }\end{array}$ & RPR-S \\
\hline & $\begin{array}{l}\text { Repair-Other (RPR-O) whereby } \\
\text { another participant (not the } \\
\text { 'speaker' of the trouble-source) } \\
\text { carries out the repair. }\end{array}$ & $\begin{array}{l}\text { Participant } A>>\text { seeing more work brings on more } \\
\text { stress thus ness gets done in the end } \\
\text { Participant } B>>\text { or less }\end{array}$ & RPR-O \\
\hline
\end{tabular}


Findings from the transcript dataset are presented below on participant contributions to discussions categorized by TASK and Off Topic turn types, which when taken together, could indicate the presences of cognitive, teaching and social elements in the online synchronous interactions.

\section{Results}

This section first presents the survey results from student experiences of learning support defined as the extent of help perceived to be available from the tutor and peers on clarifying content issues during tutorial discussions. This is followed by results from the discourse analysis of chat transcripts on turn types indicative of cognitive, teaching and social elements in the discussions.

\section{Survey Results on Tutor/Peer Learning Support}

The extent of tutor learning support perceived to be available during online discussion was measured by the following question where respondents indicated their extent of agreement on a 4-point scale from Strongly Agree (SA) to Strongly Disagree (SD).

Q.3a: The tutor clarified issues on content that were raised during the discussion.

Results from a between group comparison (Figure 5) show

- $100 \%(8) \mathrm{G} 4$ respondents agreed $(S A \& A)$ that the tutor clarified issues on content during tutorial discussions compared to $92.3 \%$ (12) G1 respondents.

- more intense agreement $(S A)$ in G4 that the tutor clarified issues on content during tutorial discussions.

Group 1: Extent of tutor learning support (Q.3a)

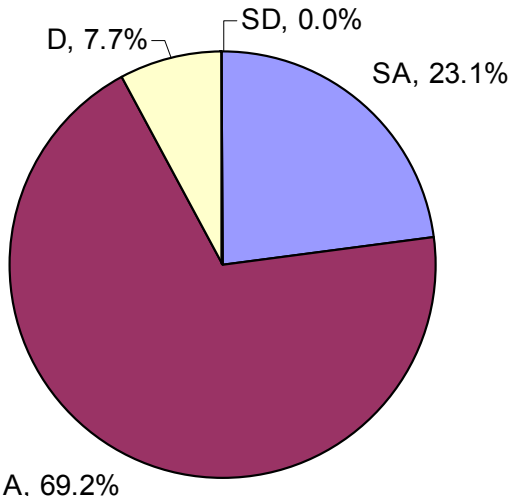

Group 4: Extent of tutor learning support (Q.3a)

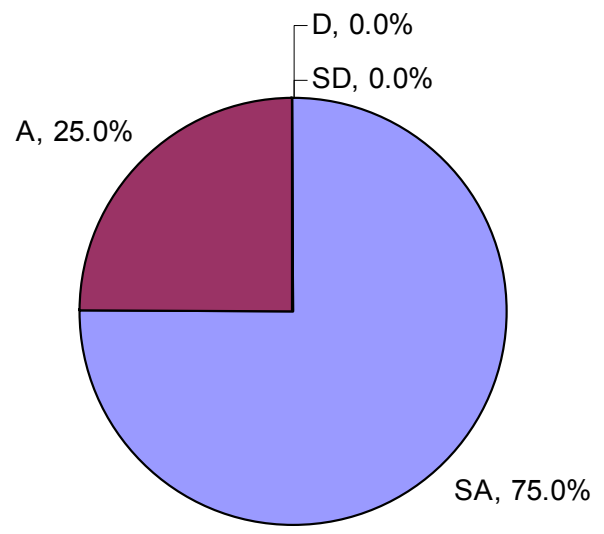

Figure 5: Extent of Tutor Learning Support (Groups 1 and 4)

The extent of peer learning support during online discussion was measured by a set of questions on the availability of clarification and different ideas from other students in the tutorial group. A between group comparison (Table 3) found

- more intense agreement $(S A)$ in G4 that peers clarified issues and contributed different ideas during discussions.

- overall greater agreement $(S A \& A)$ among G4 respondents $(100 \%)$ on the availability of clarification and different ideas from peers compared to G1 (84.6\%). 
Table 3: Extent of Peer Learning Support (Groups 1 and 4)

\begin{tabular}{|c|c|c|c|c|c|c|}
\hline & & $S A^{*}$ & $A^{*}$ & $D^{*}$ & $S D^{*}$ & $U J^{*}$ \\
\hline \multirow{2}{*}{$\begin{array}{l}3 \mathrm{~b} \text {. The other students clarified issues on } \\
\text { content that were raised during the discus- } \\
\text { sion }\end{array}$} & G1 & $2(15.4 \%)$ & $9(69.2 \%)$ & $2(15.4 \%)$ & $0(0.0 \%)$ & $-* *$ \\
\hline & G4 & $4(50.0 \%)$ & $4(50.0 \%)$ & $0(0.0 \%)$ & $0(0.0 \%)$ & $-* *$ \\
\hline \multirow{2}{*}{$\begin{array}{l}5 \mathrm{~g} \text {. The other students contributed different } \\
\text { ideas to the discussion }\end{array}$} & G1 & $2(15.4 \%)$ & $9(69.2 \%)$ & $2(15.4 \%)$ & $0(0.0 \%)$ & $0(0.0 \%)$ \\
\hline & G4 & $3(37.5 \%)$ & $5(62.5 \%)$ & $0(0.0 \%)$ & $0(0.0 \%)$ & $0(0.0 \%)$ \\
\hline
\end{tabular}

\section{Discussion on Survey Findings}

Even as comparative group analyses revealed greater agreement in G4 on the availability of tutor and peer learning support, in general, there was agreement $(S A \& A)$ in both groups that such forms of support were available during the online learning process. When teaching presence is assumed to be reflected in events of direct instruction and/or facilitation by the tutor and/or studentpresenters, and cognitive presence is held to be reflected in the exchange of idea and information during discussion, it is reasonable to conclude that survey findings of such efforts by both tutor and student participants in the clarification and provision of different ideas indicate the presences of cognitive and teaching elements in the online synchronous interactions.

\section{Discourse Analysis Results on Turn Types}

While the student self-reports of learning experiences offer one perspective on the phenomena, further insight could be gained from the analyst's interpretation of interactions from the transcripts. Such triangulation of perception survey and discourse analytical methods in conjunction with data from participant self-reports and transcripts could add "rigor, breadth, complexity, richness, and depth" (Denzin \& Lincoln, 2000, p.5) to this research effort. Findings from the discourse analysis of transcript data on participant contributions to discussions, categorized by TASK and Off Topic turn types, are presented below.

The ESA scheme categorizes contributions within episode boundaries as TASK, Off-Topic (OT) and Repair (RPR) turns. Cognitive presence could be represented by contributions coded as TASK turns while teaching and social presences could be represented by contributions subcategorized as OT-Administration (OT-A) and OT-Social (OT-S) respectively. OT-Technical (OT-T) turns could be held to reflect the technology-based virtual environment where the educational interactions are situated.

It should be noted the application of this measure raises a methodological question: Would the number of turns produced by presenters be considerably different from other students in the group as to preclude quantitative comparisons of turns produced for all episodes? This study adopted the assumption, held in Sudweeks and Simoff (2005), namely, given that the presenter would be expected to contribute more turns than the others, but each student would also be appointed as presenter, it was assumed that "contributions to the discussions from each participant were potentially equalised" (p.7) across all tutorial sessions/episodes examined.

Results from a between group comparison (Table 4) show the following:

- TASK, OT and RPR turn types were produced by both groups in tutorial discussions.

- On average, G4 participants contributed more turns of every turn type for all episodes, compared to G1. However, a further comparison of TASK and OT turns revealed that G4 participants produced a lower percentage of TASK turns in tandem with a higher percentage of OT turns, compared to G1, which suggests greater efforts by G4 in establishing teaching and social presences during the collaborative learning process. 
Table 4: Frequency of Turns by Turn Types (Groups 1 and 4)

\begin{tabular}{|c|c|c|c|c|c|c|c|c|c|}
\hline G1 & & & of Tur & & G4 & & & fTurns & \\
\hline No. & $T A S K$ & $O T$ & $R P R$ & ALL TURNS* & No. & TASK & $O T$ & $R P R$ & ALL TURNS* \\
\hline 1. Derek\# & 103 & 7 & 1 & 111 & 1. Evan & 217 & 53 & 7 & 276 \\
\hline 2. Max & 129 & 21 & 2 & 152 & 2. Bill & 111 & 57 & 1 & 169 \\
\hline 3. Alvin & 291 & 26 & 3 & 320 & 3. Mike & 179 & 40 & 1 & 220 \\
\hline 4. Cliff & 175 & 20 & 1 & 196 & 4. Eric & 424 & 165 & 7 & 596 \\
\hline 5. Colin & 81 & 11 & 0 & 92 & 5. Karl & 146 & 28 & 1 & 175 \\
\hline 6. $\quad$ Ted & 144 & 12 & 0 & 156 & 6. Jack & 395 & 173 & 7 & 575 \\
\hline 7. Sam & 121 & 3 & 0 & 124 & 7. Ian & 393 & 143 & 9 & 545 \\
\hline 8. Diane & 244 & 48 & 3 & 295 & 8. $\quad$ Pete & 245 & 23 & 2 & 270 \\
\hline 9. James & 79 & 8 & 0 & 87 & 9. Robin & 239 & 172 & 6 & 417 \\
\hline 10. Alan & 57 & 0 & 1 & 58 & 10. Lim & 213 & 39 & 0 & 252 \\
\hline 11. Jason & 100 & 11 & 1 & 112 & 11. Fay & 552 & 184 & 8 & 744 \\
\hline 12. Scott & 69 & 16 & 0 & 85 & Total & 3114 & 1077 & 49 & 4239 \\
\hline 13. Barry & 120 & 36 & 1 & 157 & $\%$ & 73.5 & 25.4 & 1.2 & 100.0 \\
\hline 14. Tony & 200 & 38 & 2 & 240 & AV & 283 & 98 & 5 & 385 \\
\hline 15. Wendy & 215 & 25 & 2 & 242 & & & & & \\
\hline 16. Rachel & 36 & 40 & 0 & 76 & & & & & \\
\hline Total & 2164 & 322 & 17 & 2503 & & & & & \\
\hline$\%$ & 86.5 & 12.9 & 0.7 & 100.0 & & & & & \\
\hline AV & 135 & 20 & 1 & 156 & & & & & \\
\hline
\end{tabular}

*ALL TURNS comprises the total number of turns within an episode that have been coded as TASK, OT and RPR. \#To ensure confidentiality of participant identity, the names used here are pseudonyms except for Lim (author) and Fay who had waived her privacy rights in the context of this research project.

A between group comparison on the distribution of OT turns (Figure 6) revealed that both groups produced OT turns of each sub-category in approximately the same percentages, with OT-S constituting the greatest proportion within G1 and G4.
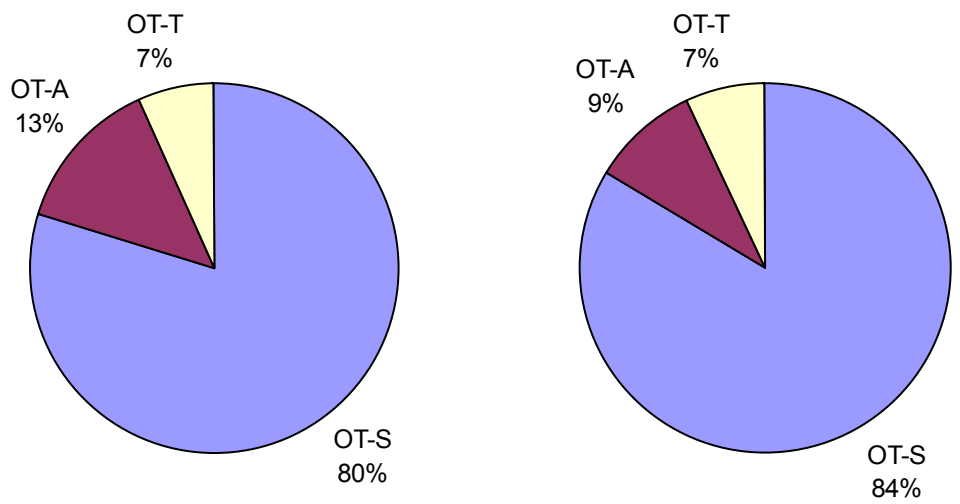

Figure 6: Distribution of Off-Topic Turns (Groups 1 and 4)

The results also highlight an interesting aspect in the distribution of OT turns by the tutors. A between tutor comparison (Table 5) revealed that both tutors produced mainly OT-S and OT-A for the respective purposes of development of social relations within each group, and class management or administration. Additionally, both tutors contributed approximately twice the average 
number of OT turns within their respective groups which was expected given their role as tutorfacilitator (Table 4).

Table 5: Distribution of OT Turn Types by Tutors

\begin{tabular}{lcccc}
\hline \multicolumn{5}{c}{ Distribution of OT Turns } \\
\hline Tutor & OT-S & OT-A & OT-T & Total \\
\hline Rachel & $27(67.5 \%)$ & $13(32.5 \%)$ & $0(0.0 \%)$ & $40(100 \%)$ \\
\hline Fay & $120(65.2 \%)$ & $50(27.2 \%)$ & $14(7.6 \%)$ & $184(100 \%)$ \\
\hline
\end{tabular}

\section{Discussion on Discourse Analysis Findings}

A between tutor comparison of TASK and OT turn types produced showed that within their respective groups, Fay contributed the highest number of TASK turns while Rachel was the lowest contributor of TASK turns that contain content directly related to the learning activities. Essentially, although both tutors participated actively in establishing social and teaching presences through OT-S/OT-A turns, the higher frequency of TASK turns by Fay suggests a greater degree of involvement in the formation of cognitive presence in G4 through the sharing of information directly related to the course content during discussions.

These findings from the transcripts were consistent with the survey results (Figure 5) that showed unanimous agreement among G4 respondents that Fay clarified issues on content during discussions, which helped to establish cognitive and teaching presences. In contrast, G1 respondents were more equivocal about the support available from Rachel with disagreement expressed by one respondent. Moreover, while most G4 respondents indicated intense agreement, the majority of G1 respondents expressed less emphatic agreement over the availability of tutor support during discussions.

In summary, survey findings from both tutorial groups indicated the presences of cognitive and teaching elements as student perceptions of tutor and peer efforts in clarifying and providing different ideas during discussions. The survey results were consistent with findings from discourse analysis of transcripts that showed the contribution of the TASK turns by tutors and students, which convey content directly related to the learning activities, hence indicating the presence of the cognitive element in the interactions. OT turns were found to be contributed in both groups and a finer analysis showed that OT-S, OT-A, and OT-T turns were produced for conveying social meanings, dealing with administrative and technical matters respectively. Additionally, Rachel and Fay were found to produce mainly OT-S and OT-A turns for the development of social relations and class management. These findings further suggest that social and teaching presences were also established during the interactions. Overall, when interpreted within the COI model, the findings suggested that all three elements of cognitive, social and teaching presences that constitute an effective online educational experience were present in the virtual learning environment of chat tutorials.

\section{Conclusion}

In examining the applicability of the COI model to online synchronous educational interaction within the virtual learning communities of two tutorial groups, findings from survey and discourse analyses suggested that the elements of cognitive, teaching and social presences were evident in moderated discussions. Hence, it could be concluded that the online synchronous learning environment, presented in this case, encompasses all three elements deemed prerequisites for a successful higher education experience (Garrison et al., 2000). These findings could guide greater experimentation by educators in extending the range of online interactions available to distant 
learning parties to encompass not only those facilitated by asynchronous but also synchronous CMC technologies.

A noteworthy finding from comparative group analysis was the varying proportions of each element between groups and tutors. While it is beyond the scope of this paper to suggest the ideal proportions of each element that would constitute the most effective educational experience, the marked differences found between the tutors' efforts in formation of cognitive presence should be a matter of concern in terms of their implications for collaborative-constructive learning processes. From the sociocultural constructivist perspective that the learner's potential capacity for intellectual growth is enhanced by scaffolding in the form of tutor/peer support through interaction, Rachel's negligible contribution of TASK turns, compared to Fay, could imply that G1 students experienced a loss of scaffolding from a more knowledgeable source which could result in an overall diminished online educational experience. It is therefore recommended that the cyclical activity of reflection on educator practice be adopted by online tutors to enhance awareness of the effects of the three mutually interacting and reinforcing elements of cognitive, social, and teaching presences on the online educational experience. Finally, a possible area for future investigation stemming from these findings is the relationship between student experiences of the online synchronous collaborative group learning processes and the quality of their coursework produced.

\section{References}

Anderson, T. (2004). Teaching in an online context. In T. Anderson \& F. Elloumi (Eds.), Theory and practice of online learning (pp. 273-294). Canada: Athabasca University.

Anderson, T., \& Garrison, D. (1998). Learning in a networked world: New roles and responsibilities. In C. Gibson (Ed.), Distance learning in higher education. (pp. 97-112). Madison WI: Atwood Publishing.

Anderson, T., Rourke, L., Garrison, D., \& Archer, W. (2001). Assessing teaching presence in a computer conferencing context. Journal of Asynchronous Learning Networks, 5(2), 1-17.

Austin, J. (1962). How to do things with words. Oxford: Clarendon Press.

Brown, G., \& Yule, G. (1983). Discourse analysis. Cambridge: Cambridge University Press.

Chou, C. (2002). A comparative content analysis of student interaction in synchronous and asynchronous learning networks. Paper presented at the 35th Annual Hawaii International Conference on System Sciences, Hawaii.

Coulthard, M., \& Brazil, D. (1992). Exchange structure. In M. Coulthard (Ed.), Advances in spoken discourse analysis (pp. 50-78). London: Routledge.

Cox, G., Carr, T., \& Hall, M. (2004). Evaluating the use of synchronous communication in two blended courses. Journal of Computer Assisted Learning, 20, 183-193.

Daft, R., \& Lengel, R. (1986). Organizational information requirements: Media richness and structural design. Management Science, 32(5), 554-571.

Denzin, N., \& Lincoln, Y. (2000). Introduction: The discipline and practice of qualitative research. In N. Denzin \& Y. Lincoln (Eds.), Handbook of qualitative research (2nd ed., pp. 1-28). London: Sage Publications.

Duemer, L., Fontenot, D., Gumfory, K., \& Kallus, M. (2002). The use of online synchronous discussion groups to enhance community formation and professional identity development. The Journal of Interactive Online Learning, 1(2).

Dykes, M., \& Schwier, R. (2003). Content and community redux: Instructor and student Interpretations of online communication in a graduate seminar. Canadian Journal of Learning and Technology, 29(2 Spring). 
Garrison, D. (2003). Cognitive presence for effective asynchronous online learning: The role of reflective inquiry, self-direction and metacognition. In J. Bourne \& J. Moore (Eds.), Elements of quality online education: Practice and direction (Vol. 4). Needham, MA: The Sloan Consortium.

Garrison, D., \& Anderson, T. (2003). E-learning in the 21st century. London: RoutledgeFalmer.

Garrison, D., Anderson, T., \& Archer, W. (2000). Critical inquiry in a text-based environment: Computer conferencing in higher education. Internet and Higher Education, 11(2), 1-14.

Garrison, D., Anderson, T., \& Archer, W. (2001). Critical thinking, cognitive presence, and computer conferencing in distance education. American Journal of Distance Education, 15(1), 7-23.

Hepburn, A., \& Potter, J. (2004). Discourse analytic practice. In C. Seale, G. Gobo, J. Gubrium \& D. Silverman (Eds.), Qualitative research practice (pp. 180-196). London: Sage.

Kanuka, H., \& Garrison, D. (2004). Cognitive presence in online learning. Journal of Computing in Higher Education, 15(2), 1-18.

Kneser, C., Pilkington, R., \& Treasure-Jones, T. (2001). The tutor's role: An investigation of the power of Exchange Structure Analysis to identify different roles in CMC seminars. International Journal of Artificial Intelligence in Education, 12, 63-84.

Kortti, H. (1999). On some similarities between discourse in the IRC and the conventions of spoken English. Retrieved 9 November, 2004, from http://www.student.oulu.fi/ hhkortti/proseminar-final.html

Lapadat, J. (2002). Written interaction: A key component in online learning. Journal of ComputerMediated Communication, 7(4).

Lim, H. L. (2006). Constructing learning conversations: A study of the discourse and learner experiences of online synchronous discussions. Unpublished PhD Thesis, Murdoch University, Perth, Australia.

Lipman, M. (1991). Thinking in education. New York: Cambridge University Press.

McKlin, T., Harmon, S., Evans, W., \& Jones, M. (2002). Cognitive presence in web-based learning: a content analysis of students' online discussion. Paper presented at the ITFORUM 2002.

Mercer, D. (2003). Using synchronous communication for online social constructivist learning. Paper presented at the 2003 CADE-ACED Conference, St Johns, Newfoundland.

Meyer, K. (2003). Face-to-face versus threaded discussions: The role of time and higher-order thinking. Journal of Asynchronous Learning Networks, 7(3), 55-65.

Moore, M. (1989). Three types of interaction. The American Journal of Distance Education, 3(2).

Moore, M., \& Kearsley, G. (1996). Distance education: A systems view. California: Wadsworth Publishing Company.

Murphy, K., \& Collins, M. (1997). Communication conventions in instructional electronic chats. First Monday, 2(11).

Palloff, R., \& Pratt, K. (2003). The virtual student: A profile and guide to working with online learners. San Francisco, CA: Jossey-Bass.

Patton, M. Q. (2002). Qualitative research and evaluation methods (3rd ed.). Thousand Oaks, CA: Sage.

Pawan, P., Paulus, T., Yalcin, S., \& Chang, C. (2003). Online learning: patterns of engagement and interaction among in-service teachers. Language Learning and Technology, 7(3), 119-140.

Pilkington, R. (1999). Analysing educational discourse: The DISCOUNT Scheme. Leeds: Computer Based Learning Unit, The University of Leeds.

Rourke, L., Anderson, T., Garrison, D., \& Archer, W. (2001). Assessing social presence in asynchronous text-based computer conferencing. Journal of Distance Education, 14(2).

Schegloff, E., Jefferson, G., \& Sacks, H. (1977). The preference for self-correction in the organization of repair in conversation. Language, 53(2), 361-382. 
Schwier, R., \& Balbar, S. (2002). The interplay of content and community in synchronous and asynchronous communication: Virtual communication in a graduate seminar. Canadian Journal of Learning and Technology, 28(2 Spring).

Searle, J. (1969). Speech acts: An essay in the philosophy of language. Cambridge: Cambridge University Press.

Short, J., Williams, E., \& Christie, B. (1976). The social psychology of telecommunications. London: John Wiley \& Sons.

Stacey, E. (2000). Quality online participation: Establishing social presence. In T. Evans (Ed.), Research in distance education 5 (pp. 138-253). Geelong: Deakin University.

Stein, D., \& Wanstreet, C. (2004, 6-8 October). Presence and interaction in an inquiry-based learning environment. Paper presented at the Midwest Research-to-Practice Conference in Adult, Continuing, and Community Education, Indiana University, Indianapolis, IN.

Sudweeks, F. (2003a). Connecting students with group work. In C. Constantinou \& Z. Zacharia (Eds.), Computer-based learning in science (Vol. 1, pp. 173-183). Nicosia, Cyprus: University of Cyprus.

Sudweeks, F. (2003b). The reflective learner: A framework for reflective e-learning. Paper presented at the ICIER03, Seattle, WA.

Sudweeks, F. (2004). Development and leadership in computer-mediated collaborative groups. Unpublished PhD Thesis, Murdoch University, Perth, Australia.

Sudweeks, F., \& Simoff, S. (2000). Participation and reflection in virtual workshops. Paper presented at the 3rd Western Australian Workshop on Information Systems Research, Perth, Australia.

Sudweeks, F., \& Simoff, S. (2005). Leading conversations: Communication behaviour of emergent leaders in virtual teams. Paper presented at the 38th Hawaii International Conference on System Sciences (HICSS05), Hawaii, USA.

Ubon, N., \& Kimble, C. (2004). Exploring social presence in asynchronous text-based online learning communities (OLCs). Paper presented at the 5th International Conference on Information Communication Technologies in Education, Greece.

Vygotsky, L. (1962). Thought and language. Cambridge, MA: MIT Press. Revised and edited by A. Kozulin, 1986.

Warschauer, M. (1996). Comparing face-to-face and electronic discussion in the second language classroom. CALICO Journal, 13(2-3), 7-26.

Werry, C. (1996). Linguistic and interactional features of Internet Relay Chat. In S. Herring (Ed.), Computer-mediated communication (pp. 47-64). Philadelphia, USA: John Benjamins Publishing Company.

\section{Biography}

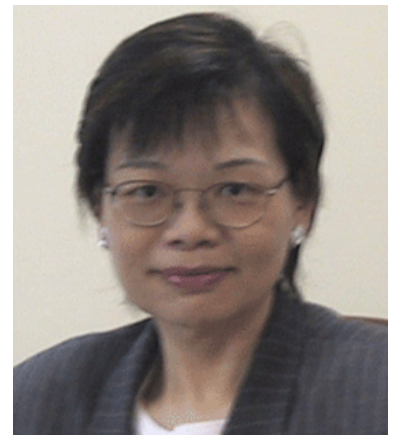

Dr. H.L. Lim is now an Assistant Professor in the Communication Department at The Petroleum Institute (Abu Dhabi, UAE). She has Bachelor (English Language, Literature) and Master (English Language) degrees, and a professional Diploma in Education from The National University of Singapore. Lim recently completed a full-time $\mathrm{PhD}$ programme in Information Technology at Murdoch University (Perth, Western Australia). Her areas of research interest are educational technology, computer-mediated communication, and distance learning. She can be contacted at hlim@pi.ac.ae, 971-2-5085324, The Petroleum Institute, P.O. Box 2533, Abu Dhabi, United Arab Emirates. 